\title{
BRAZILIAN ORTHOPEDISTS' OPINIONS AND PERCEPTIONS ON FEMOROACETABULAR IMPINGEMENT
}

\author{
Leandro Ejnisman ${ }^{1}$, Moin Khan ${ }^{2}$, Olufemi Rolland AyenI $I^{2}$, Mohit Bhandarl ${ }^{2}$, Helder de Souza Miyahara ${ }^{1}$, Jose Ricardo Negreiros Vicente ${ }^{1}$ \\ 1. Universidade de São Paulo, Faculdade de Medicina (School of Medicine), Hospital das Clínicas, Instituto de Ortopedia e Traumatologia, São Paulo, SP, Brazil \\ 2. McMaster University, Department of Surgery, Division of Orthopaedics, Hamilton, Ontario, Canada.
}

\section{ABSTRACT}

Objective: To assess the opinion of Brazilian orthopedists surgeons on the diagnosis and treatment of femoroacetabular impingement (FAl). Methods: A questionnaire was sent to several orthopedic societies around the world, including the Sociedade Brasileira de Ortopedia e Traumatologia (SBOT). This questionnaire was sent electronically and included questions on many topics related to FAl. Results: 253 Brazilian orthopedists responded the questionnaire. Sixty-eight point nine percent worked in private practice and $23.1 \%$ in academic institutions. Pain during hip rotation was the most important finding in the clinical history according to $81.8 \%$ of the respondents and the anterior impingement sign was the most important finding in the physical examination according to $88.2 \%$. Initial treatment was physiotherapy according to $86.2 \%$. Surgical treatment was hip arthroscopy according to $38.8 \%$, and via surgical hip dislocation for $14.7 \%$. Conclusion: Brazilian orthopedists' opinions on FAI are similar to their international colleagues. There is considerable discrepancy in the answers provided, demonstrating a need for future investigation on FAl, in order to institute proper treatment and diagnosis protocols. Level of Evidence V. Expert Opinion.

Keywords: Surveys and questionnaires. Physical examination. Hip. Femoroacetabular impingement.

Citation: Ejnisman L, Khan M, Ayeni OR, Bhandari M, Miyahara HS, Vicente JRN. Brazilian orthopedists' opinions and perceptions on femoroacetabular impingement. Acta Ortop Bras. [online]. 2016;24(6):322-6. Available from URL: http://www.scielo.br/aob.

\section{INTRODUCTION}

Femoroacetabular impingement (FAl) is recognized as a cause of hip pain and as a predisposing factor for early-onset osteoarthritis in young patients. ${ }^{1,2}$ This disease is characterized by abnormal conflict between the femoral head and the acetabulum due to abnormal anatomy of the femoral head-neck junction (cam type), which is aspherical, and/or acetabular overcoverage (pincer type), resulting in injury to the labrum and articular cartilage..$^{3,4}$

Treatment is initially conservative, and in cases of failure surgery is indicated. ${ }^{5}$ Surgical correction can be performed via an open or arthroscopic approach. However, there are few studies with adequate documentation on clinical and radiographic indications for the surgical correction of impingement, both via arthroscopy and via open surgery. Moreover, there is insufficient data to determine the natural history of femoroacetabular impingement. ${ }^{6}$

Given the shortage of scientific data on FAl incidence, epidemiology, prevalence and treatment methods, it is essential to understand the perceptions of orthopedic surgeons to serve as a guideline for future research and to better understand the treatment indications. This study aimed at comparing the opinion of Brazilian orthopedists with orthopedists around the world on the diagnosis, treatment and scientific evidence of FAl by means of a questionnaire.

\section{MATERIAL AND METHODS}

This study was approved by the local scientific committee (identification 13-404). A group formed by a statistician and orthopedic surgeons was responsible for determining key areas of interest to be reached. This group was called IN-FOCUS (InterNational

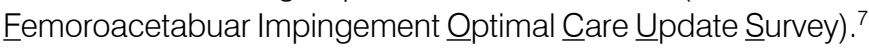
Prior orthopedic questionnaires were reviewed to ensure that all the items were appropriate and understood. ${ }^{8}$ The questions were adapted to examine the respondent's level of understanding in relation to diagnosis, surgical indication (arthroscopic or open), and the scientific data from the literature on femoroacetabular impingement. The survey involved a 'redundancy sample' in which several new surgeons were interviewed until no new item was required in the questionnaire. ${ }^{9}$

The survey was pretested to guarantee its validity with an independent group of four orthopedic surgeons specialized in treating hip disorders in young adults and to ensure that the questionnaire was tenable in the search for perceptions related to FAI.

Sections related to epidemiology, treatment options, diagnosis and quality of available scientific evidence were refined through the surgeons' feedback, seeking an improvement in content, ease of comprehension and understanding of the survey.

Author Olufemi Rolland Ayeni received a grant from the Canadian Institute of Health Research and from Smith \& Nephew; author Mohit Bhandari received grants from Smith \& Nephew, Bioventus, Stryker, Amgen, Zimmer, Moximed, Merck, Eli Lilly, Sanofi, ConMed and DePuy. All the remaining authors declare that there is no potential conflict of interest referring to this article. 
Invitations were sent by email to the members of several international orthopedic societies, including the Sociedade Brasileira de Ortopedia e Traumatologia [Brazilian Society of Orthopedics and Traumatology (SBOT)]. The survey was conducted through the SurveyMonkey website. The invitations were resent twice two weeks apart in order to increase the response rate. Restrictions were applied to ensure that each partner would answer the questionnaire only once.

\section{Statistical analysis}

All the answers were organized and analyzed on the actual SurveyMonkey website. Categorical data were presented as percentages. Since some questions had multiple correct answers, not all questions add up to 100\%. In addition, the respondents could skip questions without answering them.

\section{RESULTS}

\section{Demographic results}

Two hundred fifty-three members of the SBOT answered the questionnaire, representing $28.1 \%$ of international responses. In the international study, most of the orthopedists who answered the questionnaire were from Europe (40.7\%), followed by South America (29.3\%) and North America (14.0\%). Most of the Brazilian respondents work in private practice (68.9\%) and in academic institutions (23.1\%). Table 1 shows the answers of the orthopedists from around the world compared to the Brazilian answers.

\section{Clinical evaluation}

The most important finding in the clinical history of a patient with $\mathrm{FAl}$ is pain during hip rotation according to $81.8 \%$ of respondents, followed by groin pain (50.7\%). The most important finding in the physical examination is the anterior impingement sign (pain upon internal rotation-adduction-flexion) according to $88.2 \%$ of physicians, followed by the C sign (33.5\%).

In the respondents' opinion radiographic confirmation of the diagnosis is achieved through magnetic resonance imaging (75.9\%), radiography alone (35.0\%), computed tomography (26.6\%) and intra-articular injection of anesthetic (9.85\%). In the diagnosis of cam type FAl, the most important radiographic measurement was considered: the head-neck offset (40.9\%) and the alpha angle (37.4\%). In the diagnosis of pincer type FAl, the most important radiographic measurement was considered: crossover sign (43.84\%), center-edge angle (30.0\%) and acetabular inclination (26.6\%); $21.2 \%$ of respondents were uncertain about the answer. Table 2 shows the perceptions of Brazilian and international orthopedists on the diagnosis of FAl.

Most of the Brazilian surgeons diagnosed 1-30 cases of FAl in one year (76.9\%), only $7.98 \%$ diagnosed over 50 cases and $6.30 \%$ did not diagnose any case. Fifty-one (21.5\%) Brazilian surgeons perform hip arthroscopy, and 59 (25.1\%) perform open surgery for correction of FAl. Surgeons who perform hip arthroscopy recorded the following volumes: fewer than 10 arthroscopies

\begin{tabular}{|c|c|c|c|c|c|c|c|c|}
\hline & & Brazil & North America & South America & Europe & Asia & Africa & Australia \\
\hline \multicolumn{2}{|c|}{ Years of work } & 251 answers & 126 answers & 263 answers & 366 answers & 88 answers & 24 answers & 31 answers \\
\hline \multicolumn{2}{|c|}{ Fellowship } & $3(1.2 \%)$ & $13(10.3 \%)$ & $3(1.1 \%)$ & $18(4.9 \%)$ & $2(2.3 \%)$ & $3(12.5 \%)$ & $4(12.9 \%)$ \\
\hline & 5 & $44(17.53 \%)$ & $25(19.8 \%)$ & $44(16.7 \%)$ & $47(12.8 \%)$ & $14(15.9 \%)$ & $4(16.7 \%)$ & $8(25.8 \%)$ \\
\hline & $5-10$ & $39(15.54 \%)$ & $14(11.1 \%)$ & $41(15.6 \%)$ & $65(17.8 \%)$ & $9(10.2 \%)$ & $3(12.5 \%)$ & $4(12.9 \%)$ \\
\hline & $11-20$ & $68(27.1 \% 0$ & $17(13.5 \%)$ & $73(27.8 \%)$ & $112(30.6 \%)$ & $33(37.5 \%)$ & $6(25.0 \%)$ & $5(16.1 \%)$ \\
\hline & $20-25$ & $39(15.5 \%)$ & $10(7.9 \%)$ & $40(15.2 \%)$ & $50(13.7 \%)$ & $16(18.2 \%)$ & $4(16.7 \%)$ & $5(16.1 \%)$ \\
\hline & $>25$ & $58(23.1 \%)$ & $47(37.3 \%)$ & $62(23.6 \%)$ & $74(20.2 \%)$ & $14(16.7 \%)$ & $4(16.7 \%)$ & $5(16.1 \%)$ \\
\hline \multicolumn{2}{|c|}{ Workplace } & 251 answers & 126 answers & 263 answers & 366 answers & 88 answers & 24 answers & 31 answers \\
\hline & Academic & $58(23.1 \%)$ & $40(31.8 \%)$ & $63(24.0 \%)$ & $177(48.4 \%)$ & $39(44.3 \%)$ & $10(41.7 \%)$ & $11(35.5 \%)$ \\
\hline & Private & $173(68.9 \%)$ & $84(66.7 \%)$ & $179(68.1 \%)$ & $167(45.6 \%)$ & $43(48.8 \%)$ & $12(50.0 \%)$ & $15(48.4 \%)$ \\
\hline & Other & $20(8.0 \%)$ & $2(1.6 \%)$ & $21(8.0 \%)$ & $22(6.0 \%)$ & $6(6.8 \%)$ & $2(8.3 \%)$ & $5(16.1 \%)$ \\
\hline \multicolumn{2}{|c|}{ Subspecialty training } & 251 answers & 126 answers & 263 answers & 366 answers & 88 answers & 24 answers & 31 answers \\
\hline & Arthroplasty & $87(34.7 \%)$ & $60(47.6 \%)$ & $95(36.1 \%)$ & $239(65.3 \%)$ & $42(47.7 \%)$ & $12(50.0 \%)$ & $22(71.0 \%)$ \\
\hline & Sports & $83(33.1 \%)$ & $43(34.1 \%)$ & $86(32.7 \%)$ & $140(38.3 \%)$ & $23(26.1 \%)$ & $10(41.7 \%)$ & $16(51.6 \%)$ \\
\hline & None & $15(6.0 \%)$ & $20(15.9 \%)$ & $15(5.7 \%)$ & $18(4.9 \%)$ & $9(10.2 \%)$ & $3(12.5 \%)$ & $3(9.7 \%)$ \\
\hline & Trauma & $89(35.5 \%)$ & $13(10.3 \%)$ & $93(35.4 \%)$ & $115(31.4 \%)$ & $36(40.9 \%)$ & $9(37.5 \%)$ & $7(22.6 \%)$ \\
\hline & \begin{tabular}{|l|} 
Pediatric \\
\end{tabular} & $17(6.8 \%)$ & $5(4.0 \%)$ & $18(6.8 \%)$ & $17(4.6 \%)$ & $10(11.4 \%)$ & $2(8.3 \%)$ & $2(6.5 \%)$ \\
\hline \multicolumn{2}{|c|}{ Formal training in hip arthroscopy } & 241 answers & 123 answers & 253 answers & 356 answers & 85 answers & 22 answers & 30 answers \\
\hline & \begin{tabular}{|c|} 
Yes \\
\end{tabular} & $63(26.1 \%)$ & $59(48.0 \%)$ & $69(27.8 \%)$ & $159(44.5 \%)$ & $13(15.3 \%)$ & $5(22.7 \%)$ & $13(43.3 \%)$ \\
\hline & No & $178(73.9 \%)$ & $64(52.0 \%)$ & $184(72.7 \%)$ & $197(55.5 \%)$ & $72(84.7 \%)$ & $17(77.3 \%)$ & $17(56.7 \%)$ \\
\hline \multicolumn{2}{|c|}{ Type of Formal Training } & 63 answers & 59 answers & 69 answers & 158 answers & 12 answers & 5 answers & 13 answers \\
\hline & Fellowship & $9(14.3 \%)$ & $35(59.3 \%)$ & $9(13.0 \%)$ & $43(27.2 \%)$ & $3(25.0 \%)$ & $2(40.0 \%)$ & $10(76.9 \%)$ \\
\hline & Residency & $16(25.4 \%)$ & $23(39.0 \%)$ & $16(23.2 \%)$ & $43(27.2 \%)$ & $1(8.3 \%)$ & $1(20.0 \%)$ & $3(23.1 \%)$ \\
\hline & Course & $53(84.1 \%)$ & $40(67.8 \%)$ & $58(84.1 \%)$ & $126(79.8 \%)$ & $8(66.7 \%)$ & $3(60.0 \%)$ & $8(61.5 \%)$ \\
\hline & Visit to mentors & $25(39.7 \%)$ & $24(40.7 \%)$ & $27(39.1 \%)$ & $90(57.0 \%)$ & $3(25.0 \%)$ & $2(40.0 \%)$ & $4(30.8 \%)$ \\
\hline \multicolumn{2}{|c|}{ Annual diagnosis of FAI } & 238 answers & 122 answers & 250 answers & 354 answers & 84 answers & 22 answers & 30 answers \\
\hline & None & $15(6.3 \%)$ & $12(9.8 \%)$ & $15(6.0 \%)$ & $34(9.6 \%)$ & $17(20.2 \%)$ & $8(36.4 \%)$ & $3(10.0 \%)$ \\
\hline & $1-30$ & $183(76.9 \%)$ & $72(59.0 \%)$ & $191(76.4 \%)$ & $241(68.1 \%)$ & $60(71.4 \%)$ & $12(54.6 \%)$ & $18(60.0 \%)$ \\
\hline & $31-50$ & $21(8.8 \%)$ & $22(18.0 \%)$ & $24(9.6 \%)$ & $35(9.9 \%)$ & $4(4.8 \%)$ & $1(4.6 \%)$ & $4(13.3 \%)$ \\
\hline & More than 50 & $19(8.0 \%)$ & $16(13.1 \%)$ & $20(8.0 \%)$ & $44(12.4 \%)$ & $3(3.6 \%)$ & $1(4.6 \%)$ & $5(16.7 \%)$ \\
\hline \multicolumn{2}{|c|}{ Performs hip arthroscopy for FAl } & 237 answers & 122 answers & 249 answers & 354 answers & 84 answers & 22 answers & 30 answers \\
\hline & Yes & $51(21.52 \%)$ & $54(44.2 \%)$ & $56(22.5 \%)$ & $142(40.0 \%)$ & $16(19.1 \%)$ & $3(13.6 \%)$ & $16(53.3 \%)$ \\
\hline & No & $186(74.5 \%)$ & $68(55.7 \%)$ & $193(77.5 \%)$ & $212(60.0 \%)$ & $68(81.0 \%)$ & $19(86.4 \%)$ & $14(46.7 \%)$ \\
\hline \multicolumn{2}{|c|}{ Performs open surgery for FAI } & 235 answers & 115 answers & 247 answers & 330 answers & 84 answers & 22 answers & 26 answers \\
\hline & Yes & $59(25.1 \%)$ & $29(25.2 \%)$ & $68(27.5 \%)$ & $112(33.9 \%)$ & $28(33.3 \%)$ & $8(36.3 \%)$ & $12(46.2 \%)$ \\
\hline & No & $176(74.9 \%)$ & $86(74.8 \%)$ & $179(72.5 \%)$ & $218(66.0 \%)$ & $56(66.7 \%)$ & $14(63.6 \%)$ & $14(53.9 \%)$ \\
\hline
\end{tabular}


per year (41.1\%), between 10 and 100 cases per year (54.9\%) and more than 100 cases (3.9\%). Among the surgeons who perform open correction, $68.3 \%$ operated fewer than 10 cases in a year and $5 \%$ operated more than 100 cases. Orthopedists who perform more than 50 hip arthroscopies per year (6 surgeons) have been in clinical practice between 11 and 20 years (50\%), and between 20 and 25 years (33.3\%). One hundred percent of the surgeons in this high volume group work in private practice. After the diagnosis of $\mathrm{FAl}, 86.2 \%$ of orthopedists start treatment with physical therapy. Rest is prescribed by $38.9 \%$, surgery by $22.6 \%$, and viscosupplementation by $7.4 \%$. The main surgical indication reported was failure of conservative treatment (72.4\%), persistent hip pain (64.5\%), mechanical symptoms in the hip (56.2\%), and reduced level of sporting activity (31.0\%). Surgeons performing more than 50 arthroscopies per year indicated surgery at an earlier stage. Of these surgeons with a higher volume, $66.7 \%$ considered the initial treatment of FAl to be surgical.

Brazilian surgeons treat FAl as follows: arthroscopy (38.8\%), surgical dislocation (14.7\%), combined arthroscopic and open techniques $(9.4 \%)$, both arthroscopic and open technique (22.9\%). Table 3 shows the Brazilian surgeons' perceptions on FAl treatment and surgical technique.

\section{Clinical outcome assessment}

Clinical scores are regarded as the best method for assessing the outcome of FAl surgery by $66.9 \%$ of respondents. Other reported methods were: cartilage analysis by magnetic resonance $(39.6 \%)$, radiographic correction of $\mathrm{FAl}(31.8 \%)$, gait analysis (13.6\%) and cartilage degradation markers (12.3\%). Radiographic parameters used to assess FAl correction were: degenerative alterations (44.2\%), head-neck offset (40.9\%), alpha angle (39.6\%), crossover sign (29.2\%) and center-edge angle (22.7\%). The clinical parameters used were pain relief (76.0\%), impingement sign (53.9\%), range of motion (51.3\%) and return to sports (48.0\%). Some of the surgeons do not use clinical scores (37.0\%). The scores used varied considerably: Harris Hip Score (23.4\%), WOMAC (18.8\%), Modified Harris Hip Score (15.6\%), iHOT-33 (12.3\%), and others.

\section{Scientific evidence}

The respondents disagreed on the scientific evidence regarding the best clinical test for diagnosing FAl: $24.4 \%$ considered the evidence strong, $29.4 \%$ considered the evidence moderate and $25.0 \%$ considered the evidence weak. Similar data were reported in relation to radiographic diagnosis: $31.9 \%$ considered the evidence strong, $31.9 \%$ considered the evidence moderate and $13.7 \%$ considered the evidence weak. Evidence for the use

Table 2. Perceptions on the diagnosis.

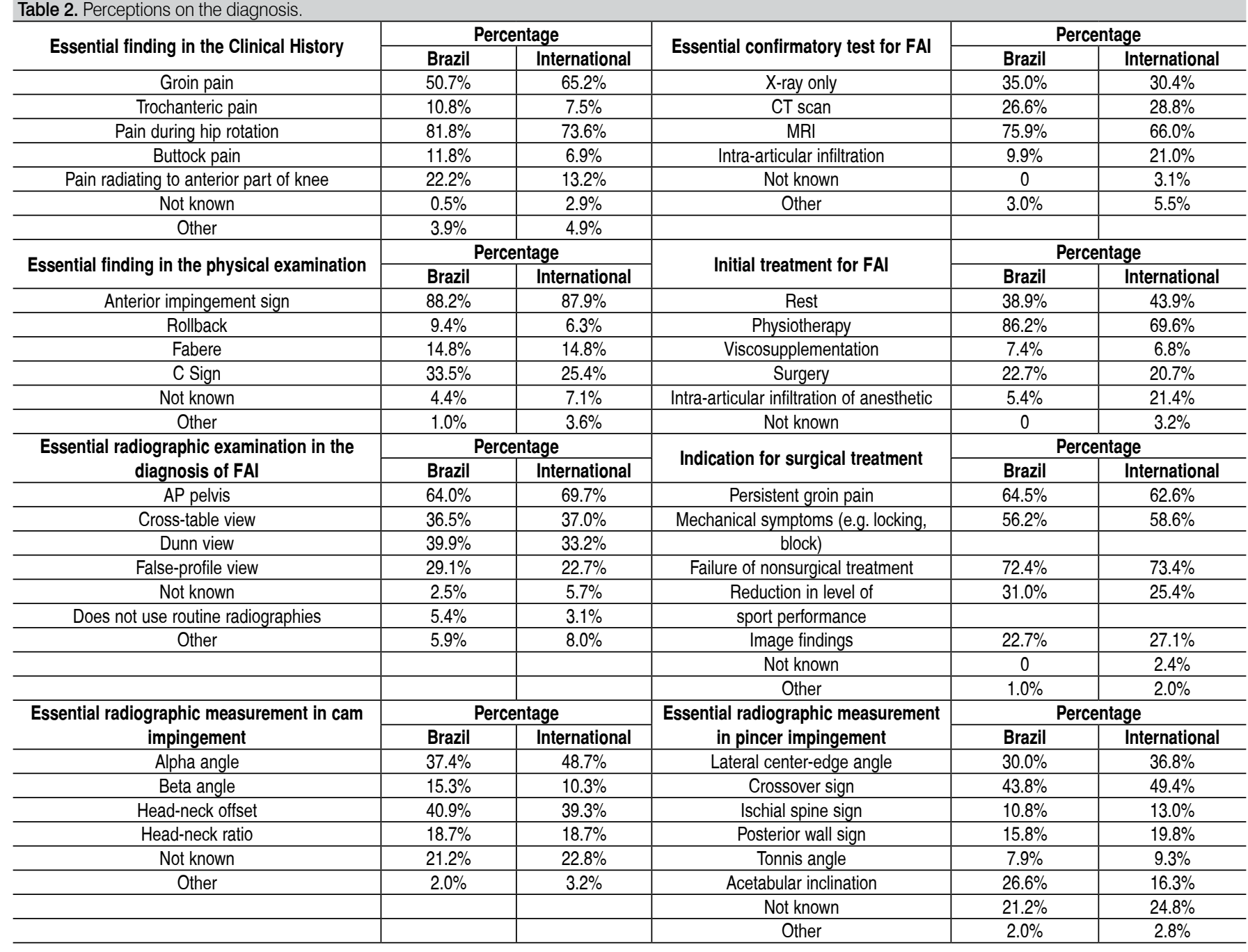


Table 3. Perceptions on surgical treatment.

\begin{tabular}{|c|c|c|c|c|c|}
\hline \multirow{2}{*}{ Treatment of FAl } & \multicolumn{2}{|c|}{ Percentage } & \multirow{2}{*}{ Care with the capsule in open surgery } & \multicolumn{2}{|c|}{ Percentage } \\
\hline & Brazil & International & & Brazil & International \\
\hline Surgical dislocation & $14.7 \%$ & $12.2 \%$ & Closes the capsule regularly & $41.8 \%$ & $41.4 \%$ \\
\hline Totally arthroscopic & $38.8 \%$ & $33.3 \%$ & Never closes the capsule & $11.2 \%$ & $8.7 \%$ \\
\hline Assisted arthroscopic & $9.4 \%$ & $5.7 \%$ & Closes the capsule in specific cases & $20.0 \%$ & $11.4 \%$ \\
\hline Both arthroscopic and open & $22.9 \%$ & $24.7 \%$ & I only perform arthroscopic surgery & $16.5 \%$ & $20.5 \%$ \\
\hline Other & $14.1 \%$ & $24.1 \%$ & Other & $10.6 \%$ & $17.9 \%$ \\
\hline \multirow{2}{*}{ Indications for open surgery } & \multicolumn{2}{|c|}{ Percentage } & \multirow{2}{*}{ Definitive treatment for FAl is performed by } & \multicolumn{2}{|c|}{ Percentage } \\
\hline & Brazil & International & & Brazil & International \\
\hline Severe deformities of the head-neck & $9.4 \%$ & $9.8 \%$ & Totally arthroscopic surgery & $53.5 \%$ & $43.8 \%$ \\
\hline junction & & & Surgical dislocation & $8.2 \%$ & $9.9 \%$ \\
\hline Acetabular dysplasia & $10.0 \%$ & $8.7 \%$ & Arthroscopic + mini incision & $18.2 \%$ & $14.8 \%$ \\
\hline Acetabular retroversion & $7.7 \%$ & $7.7 \%$ & Nonsurgical & $6.5 \%$ & $5.4 \%$ \\
\hline All the above & $23.5 \%$ & $21.4 \%$ & Not known & $10.6 \%$ & $15.2 \%$ \\
\hline Rarely in isolated cases & $28.8 \%$ & $25.2 \%$ & Other & $2.9 \%$ & $10.8 \%$ \\
\hline Not known & $18.2 \%$ & $19.7 \%$ & & & \\
\hline Other & $2.4 \%$ & $7.5 \%$ & & & \\
\hline \multirow{2}{*}{ Indication for arthroscopic surgery } & \multicolumn{2}{|c|}{ Percentage } & \multirow{2}{*}{ Ideal treatment for isolated labral lesions } & \multicolumn{2}{|c|}{ Percentage } \\
\hline & Brazil & International & & Brazil & International \\
\hline Severe deformities of the head-neck & $19.4 \%$ & $18.7 \%$ & Mechanical debridement & $21.8 \%$ & $19.4 \%$ \\
\hline junction & & & Repair with sutures & $61.2 \%$ & $56.8 \%$ \\
\hline Acetabular dysplasia & $5.9 \%$ & $3.6 \%$ & Thermal ablation & $3.5 \%$ & $3.5 \%$ \\
\hline Acetabular retroversion & $5.3 \%$ & $3.5 \%$ & Observation & $7.7 \%$ & $6.2 \%$ \\
\hline All the above & $26.5 \%$ & $21.5 \%$ & Not known & $4.7 \%$ & $9.9 \%$ \\
\hline Rarely in isolated cases & $11.2 \%$ & $12.8 \%$ & Other & $1.2 \%$ & $4.2 \%$ \\
\hline Not known & $24.1 \%$ & $24.7 \%$ & & & \\
\hline Other & $7.7 \%$ & $15.2 \%$ & & & \\
\hline \multirow{2}{*}{$\begin{array}{l}\text { Preference for capsular management } \\
\text { in Arthroscopy }\end{array}$} & \multicolumn{2}{|c|}{ Percentage } & \multirow{2}{*}{ Ideal treatment for focal pincer impingement } & \multicolumn{2}{|c|}{ Percentage } \\
\hline & Brazil & International & & Brazil & International \\
\hline Closes the capsule regularly & $17.7 \%$ & $12.3 \%$ & $\begin{array}{c}\text { Pincer decompression } \\
\end{array}$ & $17.7 \%$ & $14.9 \%$ \\
\hline Never closes the capsule & $32.4 \%$ & $36.0 \%$ & $\begin{array}{l}\text { Labral detachment, pincer decompression and labral } \\
\text { refixation }\end{array}$ & $46.5 \%$ & $41.4 \%$ \\
\hline Closes the capsule in specific cases & $21.8 \%$ & $15.8 \%$ & Pincer decompression and labral fixation & $24.7 \%$ & $23.8 \%$ \\
\hline I perform only open surgery & $17.7 \%$ & $17.5 \%$ & Not known & $8.2 \%$ & $15.8 \%$ \\
\hline Other & $10.6 \%$ & $18.4 \%$ & Other & $2.9 \%$ & $4.1 \%$ \\
\hline \multirow{2}{*}{$\begin{array}{l}\text { Access to the central compartment } \\
\text { in arthroscopy }\end{array}$} & \multicolumn{2}{|c|}{ Percentage } & & & \\
\hline & Brazil & International & & & \\
\hline Complete capsulotomy & $19.4 \%$ & $11.0 \%$ & & & \\
\hline Partial capsulotomy & $52.4 \%$ & $48.3 \%$ & & & \\
\hline No capsulotomy & $2.9 \%$ & $5.7 \%$ & & & \\
\hline Not known & $22.4 \%$ & $29.7 \%$ & & & \\
\hline Other & $2.9 \%$ & $5.3 \%$ & & & \\
\hline
\end{tabular}

of intra-articular diagnostic injections was considered even less appropriate: strong (20.0\%), moderate (25.0\%), weak (19.4\%) and very weak (11.9\%).

The surgeons also considered the evidence of conservative treatment inadequate: strong (15.0\%), moderate (26.9\%), weak (25.6\%), very weak (16.2\%). Most of the respondents (53.8\%) believed that there is evidence to consider one FAl correction technique superior to the other. Evidence of osteoplasty in the treatment of cam impingement was considered strong by $32.9 \%$, moderate by $29.7 \%$ and weak by $12.0 \%$ of the orthopedists. On the other hand, evidence of correction of pincer impingement was considered strong by $25.9 \%$, moderate by $36.1 \%$ and weak by $17.0 \%$. Evidence of the treatment of labral lesions was considered strong by $33.5 \%$, moderate by $26.6 \%$ and weak by $17.7 \%$ of respondents. Evidence of positive results following FAI surgery was considered very strong by $5.84 \%$, strong by $31.2 \%$, moderate by $35.0 \%$ and weak by $12.3 \%$ of surgeons. Evidence of the relationship between FAl and the development of hip osteoarthritis was considered very strong by $22.1 \%$, strong by $37.0 \%$, moderate by $24.0 \%$ and weak by $6.5 \%$ of orthopedists. Seventy-nine percent agreed that hip osteoarthritis is a negative predictor of post hip arthroscopy results.

\section{DISCUSSION}

In the present study we evaluated Brazilian orthopedists' opinions of FAl, and compared them with colleagues around the world. The Brazilian answers were very similar to international answers, demonstrating that Brazil is at the forefront of hip preservation surgery. In analyzing the academic background of the questionnaire respondents we can see that hip pain treatment is performed mainly by orthopedists specialized in arthroplasty, sports medicine and trauma. We also found that only $26.1 \%$ have formal training in hip arthroscopy. These figures are similar to the rest of South America, Asia and Africa, but differ from the US, Europe and Australia, where almost half of the respondents have formal training in hip arthroscopy. In Brazil, much of this training involves courses and visits to mentors; residency and fellowship training is much less common. A possible explanation for this lack of formal training is the shortage of healthcare facilities with hip arthroscopies available in the public system. Most arthroscopies in Brazil are performed in private practice, where there are fewer residents. The Brazilians' opinions on the diagnosis and initial treatment of FAl are very similar to the international responses. Groin pain 
is considered an essential finding in the patient's clinical history and the anterior impingement sign essential in the physical examination. As regards diagnostic imaging, $75.9 \%$ consider MRI essential. A difference found between Brazilians and foreigners is the use of intra-articular infiltration as a diagnostic method. Among Brazilian 9.9\% use infiltration, while $21.0 \%$ of foreigners use this method. Most Brazilians and foreigners start the treatment with rest and physical therapy, while approximately $20 \%$ start with surgery. The main surgical indications are failure of nonsurgical treatment, persistent groin pain and mechanical symptoms. The conservative treatment of FAl remains highly controversial. There is no clear indication whether it should be performed, how and for how long. ${ }^{10}$ Future surveys should seek these answers.

The answers regarding surgical treatment reflect the uncertainties found in the literature. Indications for open or arthroscopic treatment are not yet clear. Recent studies indicate adequate corrections via the arthroscopic approach, but the open approach would be more effective in cases of more posterior cam deformity. ${ }^{11}$ Brazilian orthopedic surgeons tend to opt for arthroscopic treatment of FAI (38.8\% of orthopedists use arthroscopy while $14.7 \%$ use surgical dislocation). New questionnaires could assess the cause of this discrepancy. We believe that the decision on which technique to use is not only related to the surgeon's option, but also to the availability of materials at each facility.

The evaluation of the surgeons' opinion on scientific evidence related to FAl shows that many aspects related to the treatment of this condition still require further scientific research. In analyzing the international data of the IN-FOCUS study, we believe that knowledge of FAl is at a "turning point". ${ }^{7}$ According to McCulloch et al., ${ }^{12}$ the evolution of surgical techniques follows a pre-established innovation cycle model. Under this concept, new surgical techniques are developed by pioneers, usually trendsetters who develop the basic concepts of the technique. Over time, indications expand, there is a refinement of the technique and clinical studies begin. At this moment, there is a rapid turnaround with an increase in the number of surgeons using the technique. We believe that FAl is at this "turning point".

Our study has some limitations. Questionnaires were sent in English, which may have limited the response of some Brazilian orthopedists not familiar with this language. Furthermore, some physicians may not be familiar with survey webpages such as SurveyMonkey, which may have curtailed some surgeons, particularly the older ones. In the future, similar Brazilian surveys should be conducted in Portuguese either face to face or by conventional mail with the aim of reducing these biases.

\section{CONCLUSION}

The diagnosis and treatment of FAl has been growing exponentially in Brazil and in the world, but diagnostic criteria, surgical indications and treatment methods remain controversial. Perceptions of Brazilian orthopedists are similar to the opinions of international surgeons.

AUTHORS' CONTRIBUTIONS: Each author contributed individually and significantly to the development of the manuscript. LE (0000-0002-9866-1960)*, HSM $(0000-0002-2532-2685)^{\star}$ and JRNV $(0000-0003-3528-9249)^{*}$ were the principal contributors in the writing of the manuscript. MK (0000-00028237-8095)*, ORA (0000-0003-4219-8564)* and MB (0000-0003-3556-9179)* drafted the questionnaire and collected the data. MK, MB and ORA assessed the statistical analysis data. LE, HSM and JRNV carried out the bibliographic research and the review of the manuscript, in addition to contributing to the intellectual concept of the study. ${ }^{*}$ ORCID (Open Researcher and Contributor ID).

\section{REFERENCES}

1. Ganz R, Parvizi J, Beck M, Leunig M, Nötzli H, Siebenrock KA. Femoroacetabular impingement: a cause for osteoarthritis of the hip. Clin Orthop Relat Res. 2003;(417):112-20.

2. Ejnisman L, Philippon MJ, Lertwanich P. Acetabular labral tears: diagnosis, repair, and a method for labral reconstruction. Clin Sports Med. 2011;30(2):317-29.

3. Lavigne M, Parvizi J, Beck M, Siebenrock KA, Ganz R, Leunig M. Anterior femoroacetabular impingement: part I. Techniques of joint preserving surgery. Clin Orthop Relat Res. 2004;(418):61-6.

4. Beck M, Kalhor M, Leunig M, Ganz R. Hip morphology influences the pattern of damage to the acetabular cartilage: femoroacetabular impingement as a cause of early osteoarthritis of the hip. J Bone Joint Surg Br. 2005;87(7):1012-8.

5. Amanatullah DF, Antkowiak T, Pillay K, Patel J, Refaat M, Toupadakis CA, et al. Femoroacetabular impingement: current concepts in diagnosis and treatment. Orthopedics. 2015;38(3):185-99.

6. Audenaert EA, Peeters I, Van Onsem S, Pattyn C. Can we predict the natural course of femoroacetabular impingement? Acta Orthop Belg. 2011;77(2):188-96.

7. Khan M, Ayeni OR, Madden K, Bedi A, Ranawat A, Kelly BT, et al. Femoroacetabular Impingement: Have We Hit a Global Tipping Point in Diagnosis and
Treatment? Results From the InterNational Femoroacetabular Impingement Optimal Care Update Survey (IN FOCUS). Arthroscopy. 2016;32(5):779-87.

8. Ayeni OR, Belzile EL, MusahI V, Naudie D, Crouch S, Sprague S, et al. Results of the PeRception of femOroaCetabular impingEment by Surgeons Survey (PROCESS). Knee Surg Sports Traumatol Arthrosc. 2014;22(4):906-10.

9. Bhandari M, Fong K, Sprague S, Williams D, Petrisor B. Variability in the definition and perceived causes of delayed unions and nonunions: a cross-sectional, multinational survey of orthopaedic surgeons. J Bone Joint Surg Am. 2012;94(15):e1091-6.

10. Wall PD, Fernandez M, Griffin DR, Foster NE. Nonoperative treatment for femoroacetabular impingement: a systematic review of the literature. PM R. 2013;5(5):418-26

11. Bedi A, Zaltz I, De La Torre K, Kelly BT. Radiographic comparison of surgical hip dislocation and hip arthroscopy for treatment of cam deformity in femoroacetabular impingement. Am J Sports Med. 2011;39(Suppl):20S-8S.

12. McCulloch $P$, Altman DG, Campbell WB, Flum DR, Glasziou $P$, Marshall JC, et al. No surgical innovation without evaluation: the IDEAL recommendations. Lancet. 2009;374(9695):1105-12. 